\section{Age-dependent magnitude and time course of early light adaptation}

\author{
JOSEPH F. STURR, SUSAN A. KELLY, and \\ DAVID A. KOBUS \\ Syracuse University, Syracuse, New York
}

and

\section{HARVEY A. TAUB \\ Veterans Administration Medical Center \\ Syracuse, New York}

Crawford (1947) demonstrated that large and rapid changes in visual sensitivity accompany an abrupt increase in retinal illumination. This has been referred to as early light adaptation (ELA) in order to distinguish these initial adjustments from those occurring after the eye has become more fully light adapted (White, Kelly, \& Sturr, 1978). Although much research has been carried out on ELA, the underlying mechanisms remain unknown. As part of a baseline condition for a recent ELA study in our laboratory (Kelly, 1979), ELA functions were measured on a large homogeneous field. Four observers showed a large threshold rise at the onset of the adapting field, with an exponential decay to steady-state level. However, a fifth observer repeatedly failed to show the large threshold overshoot. Following considerable effort to determine the cause of this difference, we suspected that age might be a major variable. The subject with the anomalous results was 47 years old, whereas all the others were in their 20s. Since there is a growing body of evidence documenting losses in temporal response properties of the aging visual system (Eriksen, Hamlin, \& Breitmeyer, 1970; Kline \& Orme-Rogers, 1978; Kline \& Schieber, 1981; Pollack, 1978; Walsh, 1976), we postulated that the ELA function would also manifest age-dependent changes. This report describes a study designed to test this hypothesis.

\section{METHOD}

\section{Subjects}

Four observers were used. S.A.K. (female, 27) and J.F.S. (male, 47) had had extensive experience as observers in visual psycho-

This research was supported in part by NEI Grant EY 01571 to J.F.S. and in part by the Medical Research Service of the Veterans Administration. Requests for reprints should be sent to Joseph F. Sturr, Vision Laboratories, Department of Psychology, Syracuse University, Syracuse, New York 13210. An earlier report of this research was given at the annual meetings of the American Academy of Optometry in Chicago in December 1980. Susan A. Kelly is now on the faculty of the Illinois College of Optometry. We wish to thank Silas Halperin of Syracuse University for his help in the statistical analysis. physics. H.A.T. (male, 44) and D.A.K. (male, 27) had had no prior experience as observers. All observers had 20/20 vision. D.A.K., J.F.S., and S.A.K. were myopic and wore corrective lenses throughout the experiment.

\section{Apparatus}

Stimuli were presented through a four-channel look-in tachistoscope (Iconix Model 6137-4). The adapting and test fields were provided by white light from two Kodak Ektagraphic Model E-2 carousel projectors falling upon ground-glass screens of separate channels of the tachistoscope. Test field (TF) size was determined by one of two circular apertures, subtending visual angles of $\mathbf{1 . 2}$ and $.3 \mathrm{deg}$, respectively. The adapting field (AF), which was determined by a rectangular stop, subtended 8.4 (horizontal) $\times$ $6.9 \mathrm{deg}$ (vertical). A red LED placed in a third channel caused a 5-min red fixation spot to be seen tangent to the left border of the AF and centered vertically. The TF was centered in the AF. The LED was comfortably visible to all observers. This fixation allowed the AF and TF to be presented at $4.2 \mathrm{deg}$ in the temporal retina of the observer's left eye. Observers looked into the tachistoscope through a $2-\mathrm{mm}$ artificial pupil. Luminance of the adapting field was controlled by fixed Kodak No. 96 neutral density filters. Test field luminance was controlled by a graded series of Kodak No. 96 neutral density filters arranged in the carousel tray. This provided a 4-log-unit range of luminance in .2-logunit steps. Before each testing session, illuminance of the test and adapting fields was determined with a Tektronix J-16 photometer and a cosine-corrected illuminance probe placed upon the groundglass screen. For the AF, illuminance measures were taken at three positions in the field: center, right, and left. For the TF, the illuminance probe was placed in the position of the aperture on the ground-glass screen.

Luminance of the test and adapting fields was calibrated with the J-16 and a 1-deg narrow-angle luminance probe placed in the position of the observer's eye. The AF was $1.17 \mathrm{~mL}$ or 11.7 photopic trolands of white light through the 2-mm artificial pupil. Stray light from the projectors and from the fixation spot in the system provided a constant retinal illuminance of .1 Td. Control of duration of the AF and TF and the relative onset between $\mathrm{AF}$ and TF (SOAs) was achieved by delivering calibrated pulses from a digital PDP/8-F computer to electronic shutters (Lafayette Model 43011 and Uniblitz Model 225L2A3X5) attached to the barrels of the projectors. Durations were calibrated with photodiodes whose output was monitored with an electronic counter (HP 5351B) and an oscilloscope (Tektronix 532). TF duration was $50 \mathrm{msec}$, with a rise time of $1.5 \mathrm{msec}$. AF duration was $1,000 \mathrm{msec}$, with a rise time of $1.5 \mathrm{msec}$.

\section{Procedure}

Prior to each session, the observer adjusted the artificial pupil so that it allowed a full view of the AF. The observer then dark adapted for $10 \mathrm{~min}$. Following dark adaptation, the observer looked through the viewing hood and started the trials by pressing a button. Detection thresholds were measured by means of a twoalternative forced-choice (2AFC) staircase procedure (Wetherill \& Levitt, 1965). The program chosen resulted in an estimate of $71 \%$ frequency of seeing. Following each $2 \mathrm{AFC}$ trial, the observer's response triggered a feedback tone indicating the actual interval in which the TF was presented. The following SOAs were used: $0,20,50,75,150$, and $500 \mathrm{msec}$. Each SOA was presented in a block of 40 trials, which took approximately 5 min to complete. The entire session, including alignment, dark adaptation, and a brief rest in the middle of the session, took about $50 \mathrm{~min}$.

Each observer was run for four sessions for each test size. The order of the SOA blocks in the first and third sessions was assigned randomly, with the exception that each session began and ended with the 500 -msec SOA. This provided a baseline measure 
for a condition closely approximating steady-state light adaptation and an assessment of any changes in sensitivity over the entire session. The second and fourth sessions were counterbalanced with the first and third sessions, respectively. Each session was on a different day. After all four subjects had been run with the large target, the sessions with the small target were then run.

\section{Results}

For each session, the mean of 10 staircase reversals was determined per SOA. The data were then averaged across sessions for the young and for the old observers. A split-plot ANOVA with repeated measures (age groups, SOA, and TF size) was carried out. Our analysis showed main effects of TF size $[F(1,2)=56.9, p<.05]$ and $\operatorname{SOA}[F(5,10)=7.5$, $\mathrm{p}<.05]$ and a significant interaction of SOA and age groups $[F(5,10)=5.7, p<.05]$. The triple interaction (age group $\times$ SOA $\times$ TF size) was not significant. Figure 1 displays the individual and the averaged data for the young observers and for the old observers for both TF sizes. Increment thresholds are plotted on the ordinate as a function of SOA on the abscissa. Each data point represents the mean of four sessions (40 staircase reversals per observer).

Figure 1 illustrates the lack of triple interaction, showing that the shapes of the ELA functions, although quite distinct for each age group, are similar

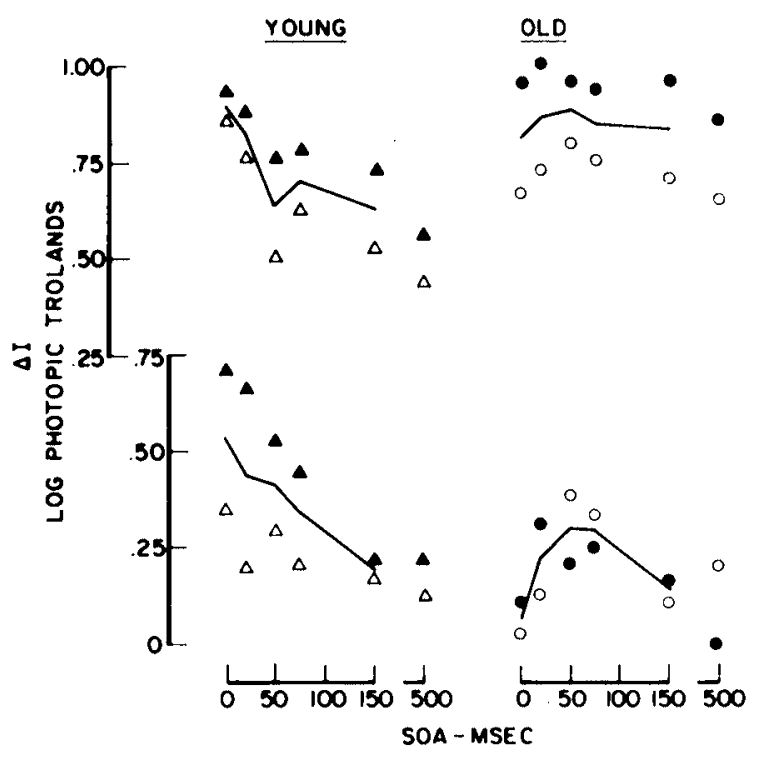

Figure 1. ELA functions for young (A, D.A.K.; $\Delta$, S.A.K.) and middle-aged (๑, H.A.T.; O, J.F.S.) observers. Each data point represents the mean of four sessions (40 staircase reversals) per observer. Curves are drawn through the mean value of each age group. Lower functions, Inside ordinate: 1.2-deg test flash. Upper functions, outside ordinate: .3-deg test flash. For all conditions, adapting field retinal illuminance was 11.7 photopic trolands. TF and AF white. Ordinate: Log retinal illuminance for TF threshold. Abscissa: Delay between onset of TF and AF. across TF sizes. The age $\times$ SOA interaction is illustrated by the two different shapes of the ELA functions for the two age groups. With the large TF, shown in the lower functions, ELA for the young observers shows the highest threshold at zero SOA, with an exponential decay out to SOA 500 . The older observers, on the other hand, show the lowest threshold at zero, with a peak near SOA 50 , and then a decline that parallels the other function. Although the younger and older observers have roughly equivalent thresholds after $500 \mathrm{msec}$ of light adaptation, the magnitudes and time courses of their early light-adaptation functions are quite different. For a smaller test probe, there is an upward threshold shift for both groups, but the characteristic shapes of the ELA functions for the young and old observers remain the same. The younger observers still show a monotonic decay function, whereas the function for the older observers, although quite attenuated, is nonmonotonic.

\section{DISCUSSION}

The measures in this study have been used to trace the time course of light adaptation following the onset of an adapting field. Younger subjects show a more vigorous response and a more rapid recovery in the near peripheral retina following the onset of a dim white photopic field. We recognize that this effect has been demonstrated in only two subjects per group. However, the experimental methods are quite rigorous, and the $2 \mathrm{AFC}$ technique controls for response bias. Furthermore, we have deliberately placed experienced and inexperienced observers in each group, so that the results cannot reflect observer sophistication. Our results provide additional evidence for those who suggest losses in transient mechanisms with advancing age (Kline \& Schieber, 1981). For example, Sekuler and Hutman (1980) report the loss of low spatial frequency contrast sensitivity in older subjects who have been matched with younger subjects for visual acuity. They argued that this spatial deficit could be caused by losses in transient mechanisms. Our adapting field has primarily low spatial frequency components (except for the edges), which should trigger transient channels, especially in the near peripheral retina. This should cause a rapidly rising and fast recovering ELA function, which was demonstrated by the younger subjects. The older observers have a slower response pattern, suggesting a loss of some of the transient channels. Our results are thus consistent with a transient/sustained model of visual function (Breitmeyer \& Ganz, 1976, 1977; Legge, 1978). However, other explanations are possible. Also, it should be pointed out that the existence of qualitatively distinct transient and sustained mechanisms has recently been challenged (Lennie, 1980).

It was surprising to us that such differences occur 
in two age groups that differ by 20 years at the most. We plan to pursue this paradigm with a larger number of subjects over a larger age span in order to see whether these temporal properties will show even greater divergence with older subjects. We also wish to examine whether there is simply a general slowing of the visual response regardless of spatial frequency of the stimulus or the retinal position stimulated.

\section{REFERENCES}

Breitmeyer, B. G., \& Ganz, L. Implications of sustained and transient channels for theories of visual pattern masking, saccadic suppression, and information processing. Psychological Review, 1976, 83, 1-36.

Breitmeyer, B. G., \& Ganz, L. Temporal studies with flashed gratings: Inferences about human transient and sustained channels. Vision Research, 1977, 17, 861-865.

Crawford, B. H. Visual adaptation in relation to brief conditioning stimuli. Proceedings of the Royal Society B, 1947, 134, 283-302.

Eriksen, C. W., Hamlin, R. M., \& Breitmeyer, R. G. Temporal factors in visual perception related to aging. Perception \& Psychophysics, 1970, 7, 354-356.
KELLY, S. A. The role of channels in early light adaptation. Unpublished doctoral dissertation, Syracuse University, 1979.

Kline, D. W., \& Orme-Rogers, C. Examination of stimulus persistence as a basis for superior visual identification performance among older adults. Journal of Gerontology, 1978, $33,76-81$.

KLINE, D. W., \& Schieber, F. Visual aging: A transient/sustained shift? Perception \& Psychophysics, 1981, 29, 181-182.

LEGGE, G. E., Sustained and transient mechanisms in human vision: Temporal and spatial properties. Vision Research, 1978, 18, 69-81.

Lennie, P. Perceptual signs of parallel pathways. Philosophical Transactions of the Royal Society B, 1980, 290, 23-37.

Pollack, R. H. A theoretical note on the aging of the visual system. Perception \& Psychophysics, 1978, 23, 94-95.

Sekuler, R., \& Hutman, L. P. Spatial vision and aging I: Contrast sensitivity. Journal of Gerontology, 1980, 35, 692-699.

WALsh, D. A. Age differences in central perceptual processing: A dichoptic backward masking investigation. Journal of Gerontology, 1976, 31, 178-185.

Wetherill, G. B., \& LEVitT, H. Sequential estimation of points on a psychometric function. British Journal of Mathematical and Statistical Psychology, 1965, 18, 1-10.

White, T. W., Kelly, S. A., \& STuRr, J. F. Large field early light adaptation. Vision Research, 1978, 18, 1678-1684.

(Manuscript received September 10, 1981; revision accepted for publication February 11, 1982.) 